\title{
Angiomatous pleomorphic xanthoastrocytoma: a case report and literature review
}

Yue-Feng Jiang ${ }^{1,2}$, Yang Liu ${ }^{1,2^{*}} \mathbb{D}$, Ye-Lin Wang ${ }^{1,2}$, Hong-Yi Cao ${ }^{1,2}$, Liang Wang ${ }^{1,2}$, Hong-Tao Xu ${ }^{1,2}$, Qing-Chang Li ${ }^{1,2}$, Xue-Shan Qiu ${ }^{1,2}$ and En-Hua Wang ${ }^{1,2}$

\begin{abstract}
Background: Pleomorphic xanthoastrocytoma is rare, accounting for $<1 \%$ of all central nervous system (CNS) neoplasms. Angiomatous pleomorphic xanthoastrocytoma is an extremely rare variant of pleomorphic xanthoastrocytoma, with only six cases reported thus far.

Case presentation: A 24-year-old Chinese female patient who presented with seizure and loss of consciousness for 15 min underwent computed tomography and magnetic resonance imaging, which revealed a mass in the left parietal lobe. Histologically, the tumor was characterized by pleomorphic tumor cells and prominent vascularity. The angiomatous region varied, ranging from a sinusoidal pattern to a venous malformation. Focal fibrinoid necrosis, hyalinization, and a moderate infiltration by lymphocytes and plasma cells were visible in the vessel wall. The tumor cells were in close proximity with adjacent small vessels. Capillaries adjacent to or extending between tumor cells were focally observed. Most tumor cells were positive for glial fibrillary acidic protein and oligodendrocyte lineage transcription factor 2. The Ki-67 index was low. Based on the patient's history, clinical data, and pathological findings, she was diagnosed with angiomatous pleomorphic xanthoastrocytoma (WHO grade II).

Conclusions: This case serves as a reminder to pathologists of the need to be aware of this rare variant of pleomorphic xanthoastrocytoma to avoid a misdiagnosis of this indolent CNS tumor and therefore inappropriate treatment.
\end{abstract}

Keywords: Pleomorphic xanthoastrocytoma, Angiomatous variant, BRAF mutation

\section{Background}

Pleomorphic xanthoastrocytoma (PXA) is an uncommon tumor of the central nervous system (CNS). It was first described as a unique entity in 1979 [1]. PXA typically develops in children and young adults, with no predilection for males vs. females. It usually develops in the superficial cortex, especially in the temporal lobes, and meningeal involvement is common [2, 3]. Uncommon sites of PXA include the cerebellum $[4,5]$, ventricle $[6,7]$, spinal cord $[8,9]$, sella $[10]$, retina $[9,11]$ and pineal gland $[11-14]$. Patients usually present with a prolonged history of seizure. Computed tomography (CT) and magnetic resonance imaging (MRI) reveal either a cystic mass with an enhancing

\footnotetext{
* Correspondence: lyonliuyang@mail.cmu.edu.cn

${ }^{1}$ Department of Pathology, the First Affiliated Hospital and College of Basic Medical Sciences, China Medical University, Shenyang 110001, China ${ }^{2}$ Institute of Pathology and Pathophysiology, China Medical University, Shenyang 110001, China
}

mural nodule or a solid mass. Histologically, PXA is charastrocytic features in storiform or fascicular array admixed with tumor giant cells that display worrisome, often severe, nuclear abnormalities. Intranuclear inclusions, eosinophilic granular bodies (EGB), and perivascular lymphocytes are often present. In general, these tumors have a very low mitotic rate and microvascular proliferation or necrosis is rare. Thus, histologically, most PXAs are WHO grade II. On occasion, however, a PXA will have a high mitotic rate $(>5$ mitoses per 10 high-power fields) and areas of necrosis, which together are features of anaplastic astrocytoma. These tumors, designated anaplastic PXA, WHO grade III instead of "PXA with anaplastic features", have been added 
to the 2016 CNS WHO as a distinct entity. Compared with PXA (WHO grade II), anaplastic PXA (WHO grade III) is associated with an aggressive behavior and the survival of affected patients is poor [15]. Variant forms in which PXA exhibits a mixed histologic pattern have been described and include "composite" tumors, harboring gangliogliomatous and xanthoastrocytomatous components, and PXAs with uncommon histological features, such as a cohesive, nesting, or alveolar growth pattern [16], a hyalinizing, angiomatous pattern [17], or a melanotic pigmentation $[18,19]$. The unusual histological appearance of PXA can complicate its diagnosis. Moreover, these tumors may be misdiagnosed if the pathologist is not familiar with the full spectrum of their variations. To improve clinical and pathological knowledge of these tumors, we present a new case of angiomatous pleomorphic xanthoastrocytoma and provide a review of previously published cases.

\section{Case presentation}

\section{Clinical history}

A 24-year-old female was admitted to our hospital. One week earlier, she had suffered a seizure that had caused a loss of consciousness lasting $15 \mathrm{~min}$. She did not have headache, vomiting, visual disturbance, or hypoacusis. Her family history was not remarkable. Neurological examination revealed no abnormalities. Contrastenhanced CT (Fig. 1a) and post-contrast T1-weighted MRI (Fig. 1b) showed a hyperintense oval mass in the left parietal lobe. Its largest dimension was $1.4 \mathrm{~cm}$. T1- weighted (Fig. 1c), post-contrast T1-weighted (Fig. 1d), T2weighted (Fig. 1f), and fluid-attenuated inversion recovery (FLAIR) (Fig. 1e) MRI showed a well-circumscribed, partially cystic mass with a focally enhancing mural nodule, minimal surrounding edema, and a mass effect in the left parietal lobe. Neuroendoscopic excision performed through a parietal hole revealed a lesion with cystic and solid components and a red-meat color in the left parietal lobe. The mass was well demarcated and adhered slightly to the surrounding normal tissue. A tumor $1.9 \times 2 \times$ $2.1 \mathrm{~cm}$ in size was completely resected. After 10 months of follow-up, the patient was alive with no tumor recurrence or metastasis and good seizure control.

\section{Materials and methods}

The tumor tissues were fixed in $10 \%$ formalin and embedded in paraffin. Sections $(4 \mu \mathrm{m})$ were cut from each paraffin block; one was stained with H\&E and the others were used in immunohistochemistry (IHC) analyses. IHC staining was performed using the streptavidinperoxidase system (Ultrasensitive; Mai Xin Inc., Fuzhou, China), according to the manufacturer's instructions, and commercially available prediluted monoclonal antibodies against the following antigens: epithelial membrane antigen (EMA), pan-cytokeratin (AE1/AE3), vimentin, glial fibrillary acidic protein (GFAP), oligodendrocyte lineage transcription factor 2 (olig2), NeuN, synaptophysin, isocitrate dehydrogenase 1 (IDH1), CD31, CD34, S100, neurofilament protein (NF), p53, CD68, inhibin- $\alpha$, D2-40, and
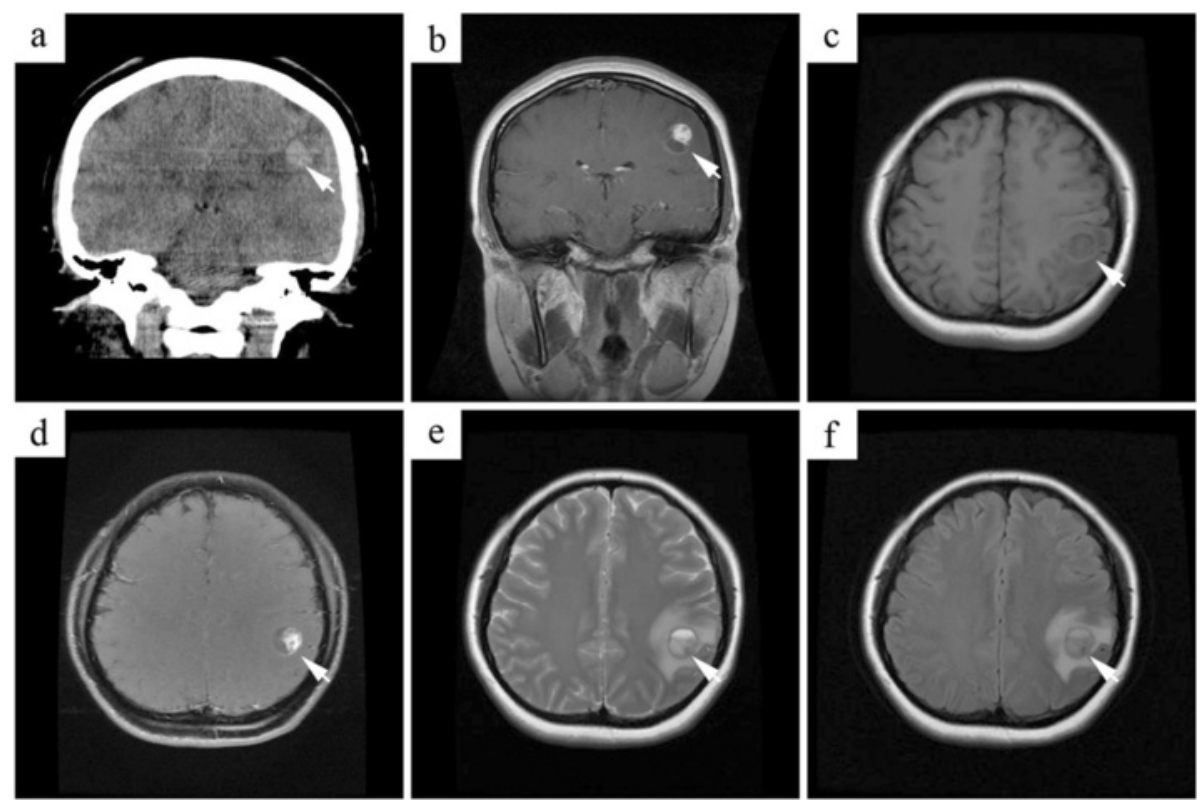

Fig. 1 Imaging examination results. a Contrast-enhanced CT reveals a hyperintense oval mass in the left parietal lobe. Post-contrast T1-weighted MRI (b coronal view), T1-weighted MRI (c horizontal view), post-contrast T1-weighted MRI (d horizontal view), T2-weighted MRI (e horizontal view), and FLAIR (f horizontal view) show a well-circumscribed, partially cystic mass with a focally enhancing mural nodule and minimal surrounding edema (both indicated by arrows) as well as a mass effect in the left parietal lobe 
Ki-67. For the negative controls, the primary antibody was replaced with PBS.

\section{BRAF ${ }^{V 600 E}$ Mutation Analysis}

The CFDA-approved human BRAF ${ }^{\mathrm{V} 600 \mathrm{E}}$ ARMSPCR kit (Amoy Diagnostics Co. Ltd., Xiamen, China) was used to detect the BRAF ${ }^{\mathrm{V} 600 \mathrm{E}}$ mutation. The quality of the extracted DNA was confirmed based on amplifications of a housekeeping gene and its analysis in the kit's HEX channel, as recommended by the manufacturer. The amplification protocol consisted of 47 cycles (one cycle of $95{ }^{\circ} \mathrm{C}$ for $5 \mathrm{~min} ; 15$ cycles of $95{ }^{\circ} \mathrm{C}$ for $25 \mathrm{~s}, 64{ }^{\circ} \mathrm{C}$ for $20 \mathrm{~s}$, and $72{ }^{\circ} \mathrm{C}$ for $20 \mathrm{~s}$; and 31 cycles of $93{ }^{\circ} \mathrm{C}$ for $25 \mathrm{~s}$, $60{ }^{\circ} \mathrm{C}$ for $35 \mathrm{~s}$, and $72{ }^{\circ} \mathrm{C}$ for $20 \mathrm{~s}$ ). FAM and HEX signals were collected during the third stage. The run files were analyzed and interpreted as specified by the manufacturer.

\section{Microscopic features}

Histologically, the tumor was characterized by markedly pleomorphic tumor cells and a highly vascular configuration. At low magnification, the entire neoplasm was invested with an abundant vascular meshwork characterized by a sinusoidal configuration and venous malformation (Fig. 2a-d). The neoplastic astrocytes that composed the tumor were surrounded by a poorly canalized configuration (Fig. 2e, f). Foci of abnormal veins of varying sizes were present within the tumor (Fig. 2g, h). The walls of these blood vessels were of variable thickness; some were thickened and showed hyaline degeneration (Fig. 2g); others were large, thin-walled vessels with irregular lumens (Fig. 2h). There was evidence of both acute and chronic hemorrhage, with foci of hemosiderin (Fig. 2i). Other features of the vessel walls were focal fibrinoid necrosis, hyalinization, and a moderate infiltration of lymphocytes and plasma cells (Fig. 2j). The presence of fibrosis or a desmoplastic reaction suggested the secondary organization of plasma proteins that had exuded through the leaky walls of the newly formed blood vessels (Fig. 2k). Together, these features suggested a hemangioma. However, the sections showed the pleomorphic histology of the tumor, with a varying cell density that, at high magnification, consisted mainly of cells with significant nuclear and cellular pleomorphism (Fig. 2l). The spindle-shaped cells, arranged in fascicular and fibrillary patterns, occurred focally (Fig. 3a). Foci of calcification (Fig. 3b) and microcystic formation (Fig. 3c) were also seen among the tumor cells, which were in close proximity with the adjacent small blood vessels. Capillaries adjacent to or protruding into the tumor cell cytoplasm were detected focally (Fig. 3d), together with mono- or multinucleated astrocytes with a foamy or vacuolated cytoplasm (Fig. 3e-g); however, typical giant xanthoastrocytes were not observed in this case. Focal clusters of small lymphocytes with intranuclear inclusions (Fig. 3h) were also evident. EGB (intensely eosinophilic or pale) and eosinophilic hyaline droplets were also observed among the tumor cells (Fig. 3i-k). Despite the focal marked pleomorphism, pseudo-palisading necrosis was not present. Mitoses were $<1$ per 10 high-power field (Fig. 3l), but atypical mitoses were absent. Silver staining revealed reticulin fibers encircling the blood vessels, but they were rare among the tumor cells (Fig. 4a). The EGBs stained red with periodic acid-Schiff (PAS) stain (Fig. 4b).

\section{Immunohistochemistry}

Immunohistochemically, the tumor cells were diffusely positive for GFAP (Fig. 4c), S100 (Fig. 4d), olig2 (Fig. 4e), synaptophysin, and vimentin, but negative for EMA (Fig. 4f), CD31, CD34 (Fig. 4g, h), NeuN, inhibin- $\alpha$, D240, and IDH1 (Fig. 4i). Some areas of the tumor stained positively for NF. Although the foamy macrophages around the tumor cells stained positively for CD68, the tumor cells were completely negative. Positive nuclear staining for p53 was detected in $\sim 50 \%$ of the tumor cells (Fig. 4j). The Ki-67 labeling index was approximately $2 \%$ (Fig. 4k).

\section{BRAF $^{\mathrm{V} 600 \mathrm{E}}$ mutation analysis}

Two recent studies, including in pediatric and in adult patients, suggested a relationship of PXA to the $\mathrm{BRAF}^{\mathrm{V} 600 \mathrm{E}}$ mutation. However, the mutation was not detected in our patient (Fig. 4l).

\section{Discussion}

Angiomatous PXA was first described by Sugita et al. in 1990 [17]. To date, the five reports in the Englishlanguage literatures describe six cases [17, 20-23]. Our patient represents the seventh case. Given the rarity of PXA, we discuss this case in the context of a literature review of the previously reported cases. The clinical and follow-up data of these cases and of the current one are summarized in Table 1. Most patients with PXA have a history of epileptic seizures. None of the patients experienced tumor recurrence or metastasis during the followup period.

The histological features of angiomatous PXA are the presence of an abundant vasculature. In our patient, the blood vessel walls were of variable thickness and some showed hyaline thickening. The abundance of blood vessels in some areas was such that the tumor resembled a hemangioma. Other features were neoplastic astrocytes and tiny blood vessels in close proximity to each other, and histological features consistent with the original description of angiomatous PXA. However, some areas of the tumor consisted of epithelioid tumor cells arranged trabecularly and surrounded by sinusoidal configurations (Fig. 2b, e, f). These sinusoidal channels were not lined by endothelial cells and were filled with erythrocytes 


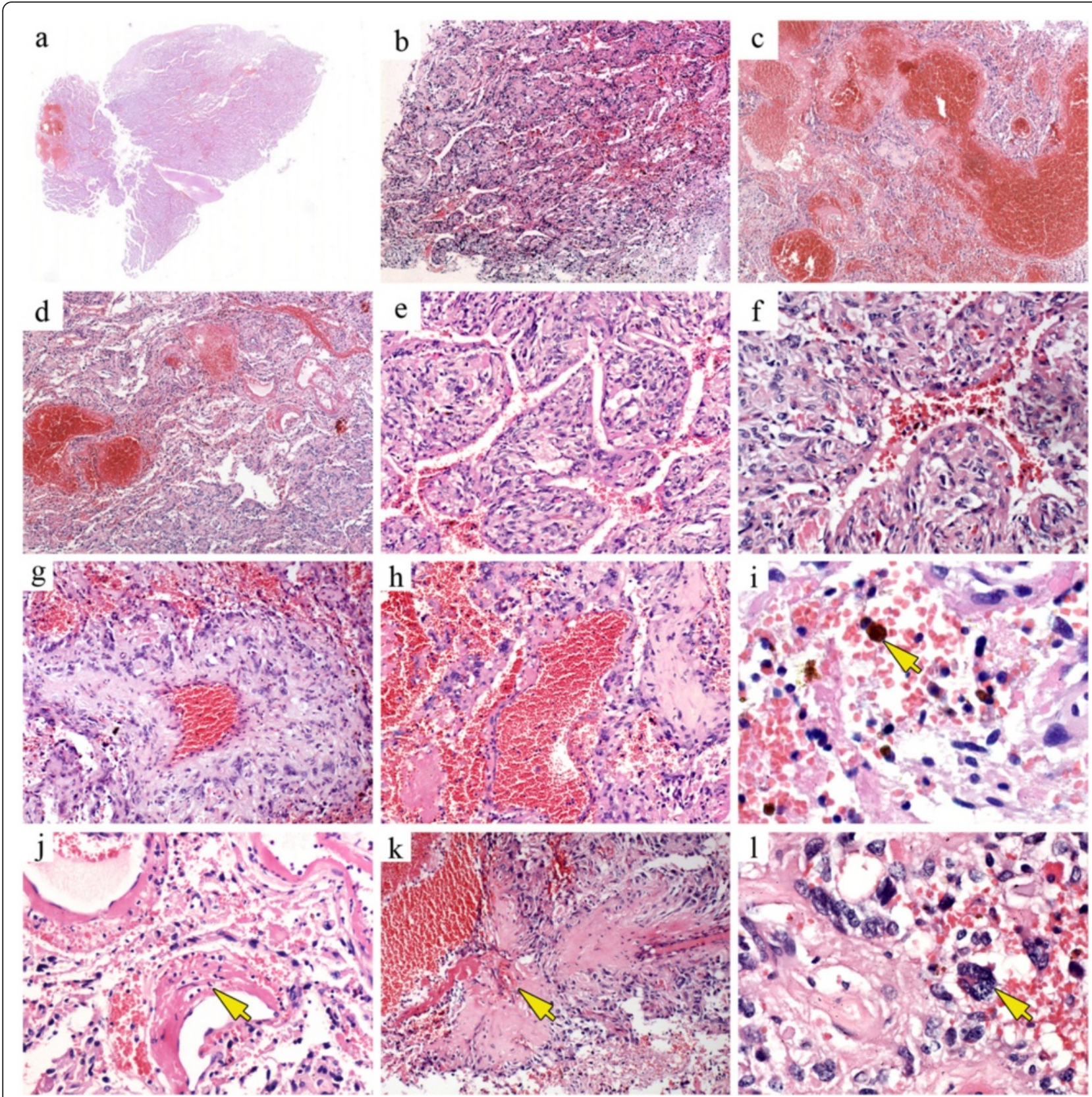

Fig. 2 Histological features of angiomatous pleomorphic xanthoastrocytoma. a-d The entire neoplasm is invested with an abundant vascular meshwork consisting of a sinusoidal configuration and venous malformation. $\mathbf{e}$, $\mathbf{f}$ The tumor is composed of neoplastic astrocytes surrounded by a poorly canalized configuration. $\mathbf{g}$, $\mathbf{h}$ Foci of abnormal veins of varying size are observed within the tumor. The blood vessel walls are of variable thickness and some show hyaline degeneration; others are large, thin-walled vessels with irregular lumens. $\mathbf{i}$ Foci of hemosiderin are present within the tumor. $\mathbf{j}$ Focal fibrinoid necrosis, hyalinization, and a moderate infiltration of lymphocytes and plasma cells are observed in the vessel wall. $\mathbf{k} \mathrm{A}$ desmoplastic reaction caused by plasma proteins that have exuded through the leaky walls of newly formed blood vessels. I The pleomorphic histology of the tumors includes a varying cell density mainly consisting of cells with significant nuclear and cellular pleomorphism. The corresponding histological features are indicated by arrows

(Fig. 2e, f). Previous reports of angiomatous PXA did not include a description of this histological pattern, which is, however, seen in other variants of PXA such as epithelioid PXA [16]. In our patient, in some areas of the tumor these two histological patterns blended imperceptibly, demonstrating the potential overlap of these two histological types in the same tumor.

The histological features of the seven known cases of angiomatous PXA are summarized in Table 2. As suggested by the name of this variant, its highly vascular 


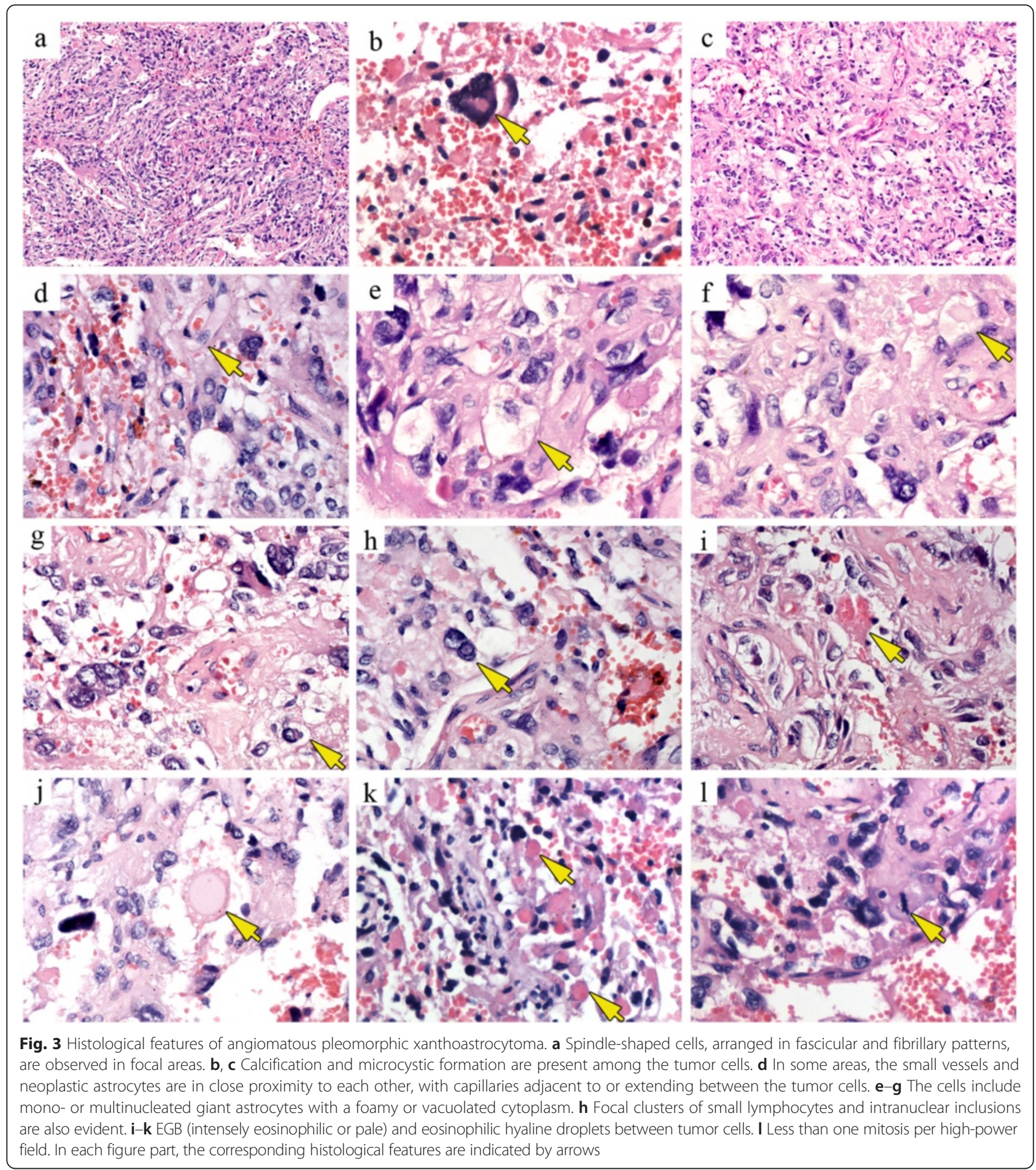

configuration mimics the pattern seen in highly vascularized or "angiomatous" meningiomas and is a common histological feature. Although the typical giant xanthomatous tumor cells were not observed in the tumor specimen from our patient, the detection of prominent multinucleated tumor cells, foci of tumor cells with a foamy or vacuolated cytoplasm, giant cells, and EGB together supported a diagnosis of PXA. Degenerative changes, such as granular bodies, microcystic changes, hyaline droplets, hyalinized blood vessel walls, hemosiderin deposition, and calcification, seen in the other six cases of PXA, were also present in the tumor of our patient. The degeneration characteristics of these tumors might be related to the indolent course of angiomatous 


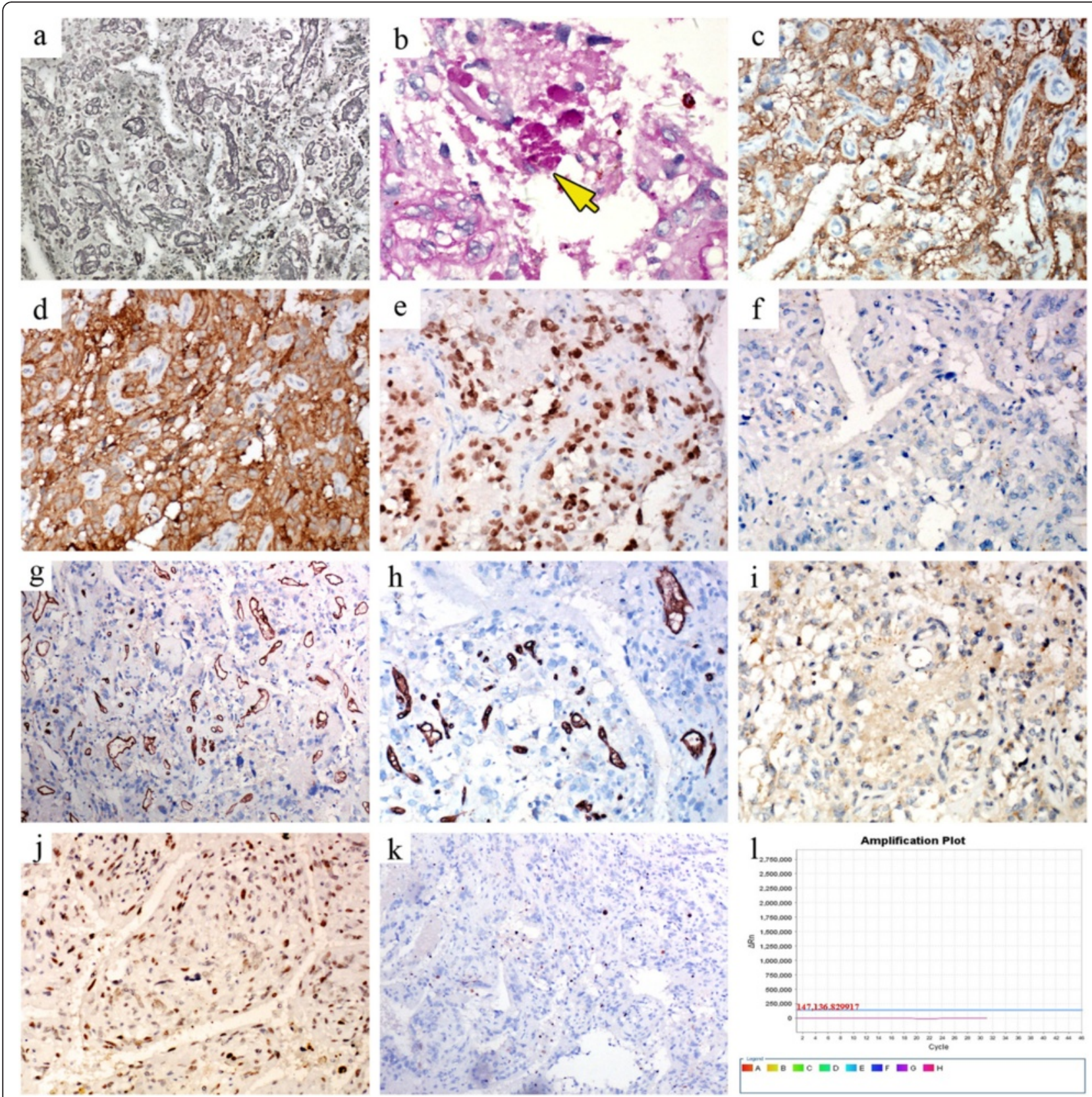

Fig. 4 Immunohistochemical and specific staining, and BRAFV600E mutation analysis. a Silver staining shows reticulin fibers encircling the blood vessels, but they are hardly present among tumor cells. b The EGBs stain red with PAS (Fig. 4b). $\mathbf{c}-\mathbf{f}$ The tumor cells are diffusely positive for GFAP, S100, and olig2, but negative for EMA. $\mathbf{g}$, $\mathbf{h}$ The tumor cells are negative but the capillaries within the tumor are positive for CD34. $\mathbf{i}$ The tumor cells are negative for IDH1. j Approximately $50 \%$ of the tumor cell nuclei stain positively for p53. $\mathbf{k}$ The Ki-67 labeling index is approximately $2 \%$. I The tumor was negative for a BRAF ${ }^{V 600 E}$ mutation. In each figure part, the corresponding histological features are indicated by arrows

PXA, as there has been no recurrence in any of the previously described patients.

The histological features of these tumors suggest their correlation with vascular malformation. However, whether these vascular changes represent a chronic clinical course or tumor degeneration, thus predicting a relatively favorable biological behavior of the PXA, is unclear. In the case presented by Sugita et al., obvious calcification of the vascular walls and extensive fibrosis were features of the tumor [17]. Lee et al. reported numerous hemosiderinladen macrophages in their PXA specimen [22]. The histological features of the tumors in our case were similar to those reported by Sugita and Lee, but there were fewer hemosiderin-laden macrophages and calcification did not involve the vascular walls, nor was it as extensive. These discrepancies suggest the slower growth of the tumors in 
Table 1 Clinical data of reported angiomatous PXA

\begin{tabular}{lllllll}
\hline Case & Authors & A/G & Tumor location & Image finds & Symptoms & Follow-up \\
\hline 1 & Sugita et al. 1990 [17] & 19/F & ND & ND & 1-year history of epileptic seizures & 10 years, NOR \\
2 & Sugita et al. 1990 [17] & 26/M & ND & ND & 6-month history of epileptic seizures & ND \\
3 & Takahabashi et al. 1995 [23] & 58/F & ND & ND & 30-year history of epileptic seizures & 2 years, NOR \\
4 & Lee et al. 1996 [22] & 45/M & left temporo-occipital lobe & cystic mass & $\begin{array}{l}\text { a 15-year history of generalized } \\
\text { tonic-clonic seizures }\end{array}$ & ND \\
5 & Sugita et al. 1999 [20] & 43/M & right temporal lobe & cystic-solid mass & $\begin{array}{l}\text { a 20-year history of generalized } \\
\text { epileptic seizures }\end{array}$ & one year, NOR \\
6 & Richard et al. 1999 [21] & 27/M & right medial frontal lobe & cystic-solid mass & $\begin{array}{l}\text { 3-year history of intermittent, } \\
\text { transient, mild, left-sided weakness }\end{array}$ & 1 year, NOR \\
7 & Present case & 24/F & left parietal lobe & cystic-solid mass & 1-week history of epileptic seizures & 10 months, NOR
\end{tabular}

$\mathrm{A} / \mathrm{G}$, Age/gender; F, female; $M$, male; ND, no data; NOR, no evidence of recurrence

the cases reported by those authors, as both patients had a long history of epileptic seizures.

Immunohistologically, the tumor cells in all seven angiomatous PXAs reported thus far consistently expressed GFAP, S100, and olig2. However, CD34 and NF expression is not a constant feature and only roughly half of the tumor cell nuclei stained positively for p53. Although the overexpression of p53 in glioma indicates a poor prognosis, the relevance of p53 in PXA remains to be clarified. In a molecular analysis of PXA by

Table 2 The histological features of angiomatous PXA

\begin{tabular}{|c|c|c|c|c|c|c|c|}
\hline \multirow[t]{2}{*}{ Histological features } & \multicolumn{2}{|c|}{$\begin{array}{l}\text { Sugita et al. } \\
1990[17]\end{array}$} & \multirow{2}{*}{$\begin{array}{l}\text { Takahabashi et al. } 1995 \text { [23] } \\
\text { Case } 3\end{array}$} & \multirow{2}{*}{$\begin{array}{l}\text { Lee et al. } 1996 \text { [22] } \\
\text { Case } 4\end{array}$} & \multirow{2}{*}{$\begin{array}{l}\text { Sugita et al. } 1999 \text { [20] } \\
\text { Case } 5\end{array}$} & \multirow{2}{*}{$\begin{array}{l}\text { Richard et al. } 1999 \text { [21] } \\
\text { Case } 6\end{array}$} & \multirow{2}{*}{$\begin{array}{l}\text { Present } \\
\text { case } \\
\text { Case } 7\end{array}$} \\
\hline & Case 1 & Case 2 & & & & & \\
\hline Highly vascular configuration & + & + & + & + & + & + & + \\
\hline Microcystic formation & ND & ND & ND & ND & + & ND & + , focal \\
\hline $\begin{array}{l}\text { storiform or fascicular growth } \\
\text { pattern with spindled cells }\end{array}$ & ND & ND & & + & ND & + & + , focal \\
\hline Anaplasic features & ND & ND & ND & - & - & - & - \\
\hline "Epithelioid" cells & ND & ND & ND & - & - & ND & + \\
\hline Pleomorphism & + & + & + & ND & + & + & + \\
\hline Foamy or vacuolated cytoplasm & + & + & + & + & + & + & + \\
\hline Giant cells & + & + & + & ND & + & + & + \\
\hline Xanthomatous tumor cells & + & + & ND & ND & + & + & - \\
\hline Dysplastic neurons & + & + & + & ND & + & + & - \\
\hline Intranuclear inclusions & ND & ND & ND & ND & ND & ND & + \\
\hline Calcification & ND & ND & ND & ND & + & + & + \\
\hline Rosenthal fibers & ND & ND & ND & ND & ND & + & - \\
\hline Eosinophilic hyaline droplets & ND & ND & ND & ND & ND & + & + \\
\hline \multicolumn{8}{|l|}{ Granular bodies } \\
\hline eosinophilic & + & + & + & + & + & + & + \\
\hline Pale & ND & ND & ND & ND & ND & ND & + \\
\hline Hemosiderin deposition & ND & ND & ND & + & - & + & + , focal \\
\hline Perivascular lymphocytes infiltration & + & + & ND & + & + & + & + \\
\hline Reticulin network & ND & ND & ND & + & - & - & - \\
\hline Mitoses & rare & rare & rare & rare & rare & rare & rare \\
\hline Necrosis & - & - & - & - & - & - & - \\
\hline Endothelial proliferation & - & - & - & - & - & - & - \\
\hline
\end{tabular}

+: the corresponding feature exists; -: the corresponding feature does not exist; ND: no data 
Tabouret et al. [24], a BRAF ${ }^{\mathrm{V} 600 \mathrm{E}}$ mutation was a common molecular characteristic. An association between BRAF-mutated PXA, reticulin fiber deposition, and CD34 expression was also described [25], while in our case, neither reticulin fiber deposition (Fig. 4a) nor CD34 expression (Fig. 4g, h) was observed, which precisely demonstrates this phenomenon from reverse. In the case reported by Yamada et al. [26], the tumor harbored both a BRAF ${ }^{\mathrm{V} 600 \mathrm{E}}$ mutation and an IDH1 R132H mutation, although the latter has been seldom identified in PXA. In our patient, BRAF ${ }^{\mathrm{V} 600 \mathrm{E}}$ mutation analysis and IDH1 R132H immunohistological staining yielded negative results (Fig. 4l, i).

Because of the prominent nuclear pleomorphism (Fig. 3e, f, g) and mesenchymal-like foci (Fig. 3a) in the tumor removed from our patient, the differential diagnosis will include giant-cell glioblastoma, gliosarcoma, ganglioglioma, and pilocytic astrocytoma. Unlike PXA, giant-cell glioblastoma and gliosarcoma typically have significant mitotic activity, microvascular proliferation, and pseudo-palisading necrosis. Neither significant mitotic activity nor pseudo-palisading necrosis were seen in the present case, and the Ki-67 labeling index was $\sim 2 \%$, which ruled out a diagnosis of giant-cell glioblastoma or gliosarcoma. Despite the abundant vasculature, glomeruloid microvascular proliferation, characteristic of glioblastoma, was not seen in this case. In addition, EGBs were prominent and are typical of PXA, but not gliosarcoma. The cystic mass with a focally enhancing mural nodule, revealed by MRI, also supports a diagnosis of PXA rather than gliosarcoma. PXA and ganglioglioma may have overlapping clinical, radiologic, and histologic features and in rare cases the two co-exist, forming a composite neoplasm. However, ganglioglioma is less pleomorphic, has a more obvious neuronal component, and lacks lipidized astrocytes. In our patient, the presence in the tumor of neoplastic astrocytes with a foamy or vacuolated cytoplasm and the negative immunostaining result for NeuN did not support a diagnosis of ganglioglioma. The tumor cells in pilocytic astrocytoma may have bizarre, atypical, or pleomorphic nuclei but their typical biphasic pattern, consisting of bipolar and loose-textured multipolar cells, was not identified in this case. In addition, angiomatous PXA should be distinguished with hemangioblastoma based on the abundant vasculature and the tumor cells with foamy or vacuolated cytoplasm. However, in hemangioblastoma, the stromal cells often label for S-100, NSE, CD56, inhibin- $\alpha$, and D2-40. Reactivity for GFAP, if present, is usually limited to entrapped astrocytes, thus seldom presents with diffuse form. In the current case, the immunophenotype (diffusely positive for olig2 and GFAP, inhibin- $\alpha-$, D2-40-) ruled out a diagnosis of hemangioblastoma.
In general, PXA has a relatively indolent clinical course. However, Kepes et al. [27] reported several instances in which local recurrences that developed at varying intervals after surgery transitioned to a more malignant type of astrocytoma (anaplastic astrocytoma or glioblastoma). Weldon-Linne et al. [28] also reported that PXA may have a less favorable course, with aggressive, malignant transformation even after a prolonged period of indolence. While malignant evolution is the exception, its occasional occurrence warns against considering PXA as benign. Tabouret et al. [24] found that the BRAF ${ }^{\mathrm{V} 600 \mathrm{E}}$ mutation was a common molecular characteristic of PXA and suggested its predictive value for progression-free survival in adult patients. However, p53 overexpression rather than a $\mathrm{BRAF}^{\mathrm{V} 600 \mathrm{E}}$ mutation was detected in the tumor from our patient. Whether their absence indicated a relatively unfavorable biological behavior remains to be determined in the long-term follow-up of our patient.

\section{Conclusion}

Our case report of angiomatous pleomorphic xanthoastrocytoma is meant to serve as a reminder to pathologists to be aware of this rare variant of PXA. The description provided herein and the review of the features of these tumors, based on previously published cases, should help to avoid a misdiagnosis of this typically indolent CNS tumor.

\section{Abbreviations \\ CNS, central nervous system; CT, computed tomography; EGB, eosinophilic granular bodies; EMA, epithelial membrane antigen; GFAP, glial fibrillary acidic protein; IDH1, Isocitrate dehydrogenase $1 ; \mathrm{IHC}$, immunohistochemistry; MRI, magnetic resonance imaging; NF, neurofilament; olig2, oligodendrocyte lineage transcription factor 2; PXA, Pleomorphic xanthoastrocytoma}

\section{Acknowledgment}

We thank the patient, who requested anonymity, for agreeing to our report and for providing a detailed medical history.

\section{Funding}

This study was supported by grants from the National Natural Science Foundation of China (No. 81302312 to Yang Liu and no. 81302192 to Liang Wang), the Natural Science Foundation of Liaoning Province (No. L2013292 to Yang Liu), and the Scientific Research Foundation for the Returned Overseas Chinese Scholars (No. 2013277 to Yang Liu).

\section{Availability of data and materials}

The datasets supporting the conclusions of this article are included within the article.

\section{Authors' contributions \\ $Y L$ analyzed the data and wrote the manuscript as a major contributor. $Y L$, $Y J, Y W$, and $H C$ performed the immunochemical staining. $L W, H X, Q L, X Q$, and EW revised the discussion section of this manuscript. All authors have read and approved the final manuscript.}

Competing interests

The authors declare that they have no competing interests. 


\section{Consent for publication}

Informed consent was obtained from the patient for the publication of this case report and any accompanying images. A copy of the written consent is available for review by the Editor-in-Chief of this journal.

\section{Ethics approval and consent to participate}

Ethical approval for this study was obtained from the Local Trials Committee of the China Medical University.

\section{Received: 10 April 2016 Accepted: 31 July 2016}

Published online: 09 August 2016

\section{References}

1. Kepes JJ, Rubinstein $\sqcup$, Eng LF. Pleomorphic xanthoastrocytoma: a distinctive meningocerebral glioma of young subjects with relatively favorable prognosis. A study of 12 cases. Cancer. 1979:44(5):1839-52.

2. Kleihues P, Cavenee WK, World Health Organization. International Agency for Research on Cancer. Pathology and genetics of tumours of the nervous system. Lyon: IARC Press; 2000.

3. Rosai J, Ackerman LV, Rosai J. Rosai and Ackerman's surgical pathology. 10th ed. Edinburgh. New York: Mosby; 2011.

4. Gil-Gouveia R, Cristino N, Farias JP, Trindade A, Ruivo NS, Pimentel J. Pleomorphic xanthoastrocytoma of the cerebellum: illustrated review. Acta Neurochir. 2004;146(11):1241-4.

5. Perry A, Giannini C, Scheithauer BW, Rojiani AM, Yachnis AT, Seo IS, et al. Composite pleomorphic xanthoastrocytoma and ganglioglioma: report of four cases and review of the literature. Am J Surg Pathol. 1997;21(7):763-71.

6. Menendez R, Fernandez J, Monti A, Sevlever G. Intraventricular pleomorphic xanthoastrocytoma: a case report. Turkish Neurosurg. 2014;24(6):987-91.

7. Yang WQ, Huang B, Liang CH. Pleomorphic xanthoastrocytoma in the latera ventricle with extensive subarachnoid dissemination: report of a case and review of the literature. Chin Med J. 2012;125(2):396-9.

8. Nakamura M, Chiba K, Matsumoto M, Ikeda E, Toyama Y. Pleomorphic xanthoastrocytoma of the spinal cord. Case report. J Neurosurg Spine. 2006; 5(1):72-5.

9. Zarate JO, Sampaolesi R. Pleomorphic xanthoastrocytoma of the retina. Am J Surg Pathol. 1999;23(1):79-81.

10. Arita K, Kurisu K, Tominaga A, Sugiyama K, Sumida M, Hirose T. Intrasellar pleomorphic xanthoastrocytoma: case report. Neurosurgery. 2002;51(4): 1079-82.

11. Snipes GJ, Horoupian DS, Shuer LM, Silverberg GD. Pleomorphic granular cell astrocytoma of the pineal gland. Cancer. 1992;70(8):2159-65.

12. Katayama K, Asano K, Shimamura N, Ogasawara Y, Naraoka M, Ohkuma H, et al. Case of pleomorphic xanthoastrocytoma with anaplastic features in the pineal gland. Brain Tumor Pathol. 2013;30(4):242-6.

13. Srinivas BH, Uppin MS, Panigrahi MK, Vijaya Saradhi M, Jyotsna Rani Y, Challa S. Pleomorphic xanthoastrocytoma of the pineal region. J Clin Neurosci. 2010;17(11):1439-41

14. Thakar S, Sai Kiran NA, Ghosal N, Hegde AS. Pleomorphic xanthoastrocytoma: a new differential diagnosis for a pediatric pineal neoplasm. Brain Tumor Pathol. 2012;29(3):168-71.

15. Louis DN, Perry A, Reifenberger G, von Deimling A, Figarella-Branger D, Cavenee WK, et al. The 2016 World Health Organization Classification of Tumors of the Central Nervous System: a summary. Acta Neuropathol. 2016; 131(6):803-20.

16. Iwaki T, Fukui M, Kondo A, Matsushima T, Takeshita I. Epithelial properties of pleomorphic xanthoastrocytomas determined in ultrastructural and immunohistochemical studies. Acta Neuropathol. 1987:74(2):142-50.

17. Sugita Y, Kepes JJ, Shigemori M, Kuramoto S, Reifenberger G, Kiwit JC, et al. Pleomorphic xanthoastrocytoma with desmoplastic reaction: angiomatous variant. Report of two cases. Clin Neuropathol. 1990;9(6):271-8.

18. Xiong J, Chu SG, Mao Y, Wang Y. Pigmented pleomorphic xanthoastrocytoma: a rare variant and literature review. Neuropathology. 2011;31(1):88-92.

19. Sharma MC, Arora R, Khanna N, Singh VP, Sarkar C. Pigmented pleomorphic xanthoastrocytoma: report of a rare case with review of the literature. Arch Pathol Lab Med. 2001;125(6):808-11.

20. Sugita Y, Hayashi I, Aoki T, Shigemori M, Morimatsu M, Okamoto Y, et al. Angiomatous variant of pleomorphic xanthoastrocytoma in a patient with a 20-year history of epilepsy. Neuropathology. 1999;19(2):190-5.
21. Hessler RB, Kfoury H, Al-Watban J, Hassounah M. Angiomatous pleomorphic xanthoastrocytoma as a component of ganglioglioma. Annals Saudi Med. 1999;19(1):48-51.

22. Lee TT, Landy HJ, Bruce JH. Arteriovenous malformation associated with pleomorphic xanthoastrocytoma. Acta Neurochir. 1996;138(5):590-1.

23. Takahashi H, Kakita A, Honda Y, Kameyama S, Tanaka R, Ikuta F. Pleomorphic xanthoastrocytoma: New ultrastructural observations. Neuropathology. 1995 15(3-4):133-7.

24. Tabouret E, Bequet C, Denicolai E, Barrie M, Nanni I, Metellus P, et al. BRAF mutation and anaplasia may be predictive factors of progression-free survival in adult pleomorphic xanthoastrocytoma. Eur J Surg Oncol. 2015; 41(12):1685-90.

25. Koelsche C, Sahm F, Wohrer A, Jeibmann A, Schittenhelm J, Kohlhof $P$, et al. BRAF-mutated pleomorphic xanthoastrocytoma is associated with temporal location, reticulin fiber deposition and CD34 expression. Brain Pathol. 2014; 24(3):221-9.

26. Yamada S, Kipp BR, Voss JS, Giannini C, Raghunathan A. Combined "Infiltrating Astrocytoma/Pleomorphic Xanthoastrocytoma" Harboring IDH1 R132H and BRAF V600E Mutations. Am J Surg Pathol. 2015;40(2):279-84.

27. Kepes JJ. Glioblastoma multiforme masquerading as a pleomorphic xanthoastrocytoma. Childs Nerv Syst. 1989;5(3):127.

28. Weldon-Linne CM, Victor TA, Groothuis DR, Vick NA. Pleomorphic xanthoastrocytoma. Ultrastructural and immunohistochemical study of a case with a rapidly fatal outcome following surgery. Cancer. 1983;52(11): 2055-63.

\section{Submit your next manuscript to BioMed Central and we will help you at every step:}

- We accept pre-submission inquiries

- Our selector tool helps you to find the most relevant journal

- We provide round the clock customer support

- Convenient online submission

- Thorough peer review

- Inclusion in PubMed and all major indexing services

- Maximum visibility for your research

Submit your manuscript at www.biomedcentral.com/submit 